\title{
UMA BREVE ANÁLISE DO ENSINO PROFISSIONALIZANTE NO BRASIL
}

Kelly Cristina Campones ${ }^{1}$

RESUMO: Este artigo é parte integrante de uma pesquisa de mestrado concluída em 2012 intitulada História, Trabalho e Educação: ensino profissionalizante do SENAI Ponta Grossa- Paraná. Entende-se que é de suma importância compreender e contextualizar historicamente as relações que tangenciaram a criação do ensino profissionalizante e, sobretudo do SENAI no Brasil; portanto, o estudo refere-se a uma breve retomada do modo de produção do sistema colonial e a sua correlação com a economia, a sociedade, o trabalho e a educação daquele período. Discorrendo sobre a influência de imigrantes no Brasil, a pesquisa avança para as primeiras iniciativas do governo relacionadas ao ensino profissional, com a criação das Escolas de Aprendizes Artífices, sob o governo de Nilo Peçanha. Ao final, contextualizamos as diferentes intervenções que vieram a institucionalizar o SENAI no Brasil.

Palavras-chave: Educação Profissionalizante. SENAI. Trabalho. Educação.

\section{A BRIEF ANALYSIS OF VOCATIONAL EDUCATION IN BRAZIL}

ABSTRACT: This article is an integral part of a master's research completed in 2012 titled: History, Work and Education: Vocational Education of SENAI Ponta Grossa Paraná. It is understood that it is of the utmost importance to understand and contextualize historically the relations that have touched the creation of vocational education, and especially the SENAI in Brazil, so the study refers to a brief resumption of the colonial system's mode of production and its correlation with the economy, society, work and education of that period; discussing the influence in Brazil, due to the coming of other ethnic groups, advancing to the first initiatives of the government related to vocational education, with the creation of the Schools of Artificers, when Nilo Peçanha was the president and, at the end, contextualizing the different interventions that came to institutionalize SENAI in Brazil.

Keywords: Vocational Education. SENAI. Job. Education.

1 Profa. Ms. da Faculdade Sagrada Família - Ponta Grossa/PR, Coordenadora do Colégio SESI. E-mail kcampones@yahoo.com.br 


\section{UNA BREVE ANÁLISIS DE LA ENSEÑANZA PROFESIONAL EN BRASIL}

RESUMEN: Este artículo es parte integrante de una investigación de maestría concluida en 2012 titulado: Historia, Trabajo y Educación: enseñanza profesional del SENAI Ponta Grossa- Pr. Se entiende que es de suma importancia comprender y contextualizar históricamente las relaciones que tangenciaron la creación de la enseñanza profesional y, sobre todo del SENAI en Brasil por lo tanto, el estudio se refiere a una breve reanudación del modo de producción del sistema colonial y su correlación con la economía, la sociedad, el trabajo y la educación de aquel período; que discutía sobre la influencia en Brasil, derivada de la venida de otras etnias, avanzando hacia las primeras iniciativas del gobierno relacionadas con la enseñanza profesional, con la creación de las Escuelas de Artífices, bajo la decisión de Nilo Peçanha $y$, al final contextualizando las diferentes intervenciones que vinieron a institucionalizar el SENAI en Brasil.

Palabras clave: Educación Profesional. SENAI. Trabajar. Educación.

\section{Introdução}

No Período Colonial, a economia brasileira fundava-se basicamente na utilização do trabalho escravo nas lavouras onde os meios de produção (terra, matéria-prima, ferramentas) ligavam-se diretamente à força de trabalho (escravo, trabalhador).

A geração de capital daquele período se dava então com ênfase na produção e utilização de poucos recursos, por meio de uma relação de submissão da força de trabalho, ou seja, historicamente no

[...] regime econômico-social escravista funda-se em um modo peculiar de conexão entre os meios de produção e o trabalho produtivo. A maneira pela qual a força de trabalho é cristalizada em produto de valor define a escravatura como uma forma singular de organização das atividades econômicas, gerando uma configuração histórico-social (IANNI, 1988, p.65).

Considera-se que, apesar das atividades laborais produtivas se basearem na força de trabalho escrava, esses trabalhadores estavam à margem da sociedade colonial, pois naquela época entendia-se que trabalho braçal "[...] trazia consigo uma sugestão de degradação [...] aparecia como uma obrigação penosa confundia-se com o cativeiro, associava-se às torturas do eito" (COSTA, 1989, p.15). 
Nessas condições, a oligarquia rural, formada pelos donos de terras, deveria manter sua condição social na geração, manutenção e absorção de riquezas dos bens produzidos pela classe considerada inferiorizada.

Com a utilização da força de trabalho escravo, o

[...] trabalho manual passava, então, a ser 'coisa de escravos' ou da 'repartição de negros' e, por uma inversão ideológica, os ofícios mecânicos passavam a ser desprezados, como se houvesse algo de essencialmente aviltante no trabalho manual, quando a exploração do escravo é que o era (CUNHA, 2005, p.16).

Dentro de uma perspectiva de desprezo para com o trabalho manual, deve-se considerar que eram também esses trabalhadores marginalizados que, de certa forma, poderiam, por meio da sua produção, elevar a movimentação econômica num determinado contexto.

Para a oligarquia rural, a principal função da Colônia era gerar riquezas para a economia central2 ${ }^{2}$ onde

[...] o sistema colonial fez prosperar o comércio e a navegação. As sociedades dotadas de monopólio [...] eram poderosas alavancas de concentração de capital. As Colônias asseguravam mercado às manufaturas em expansão e, graças ao monopólio, numa acumulação acelerada. As riquezas apresadas fora da Europa pela pilhagem, escravização e massacre refluíam para a metrópole onde se transformavam em capital (MARX, 1994, p.871).

No sistema Colonial, a força de trabalho escrava foi um meio de garantir o desenvolvimento de uma sociedade cujas ideias estavam repletas de preconceitos, principalmente com o trabalho físico. "A existência de dominadores e dominados, numa relação de senhores e escravos propiciou situações particulares, específicas, marcando a mentalidade nacional" (COSTA, 1989, p.15).

\footnotetext{
${ }^{2}$ Economia central é uma expressão utilizada para designar um sistema econômico onde as decisões sobre a produção de bens são tomadas pelo Estado.
} 
Eram estes trabalhadores que, aos poucos, desenvolviam, com sua força de trabalho, as necessidades e expectativas dos "senhores" que mantinham sua sobrevivência e cuja riqueza "[...] corrompe-se com o regime de escravidão, quando se torna resultado de opressão, de exploração" (COSTA, 1989, p.15).

Numa sociedade baseada nesse modelo, a educação se dava por meio da transmissão de conhecimentos adquiridos informalmente de experiências bem sucedidas dos antepassados, quase sempre nos ambientes familiares, cujos membros apenas reaplicavam um modelo de força de trabalho adquirido de seus antecessores, com o objetivo de preservar uma cultura aprendida. Todavia, intrinsecamente, esse modelo acabava propiciando a alienação e minimização de suas funções laborais.

Entretanto, nas relações de mediação entre trabalho e educação, percebe-se que a educação voltada à modalidade profissional, por meio da transmissão de conhecimentos de geração para geração, acabou se refletindo de forma autônoma na existência da preservação dos ofícios inerentes à vida cotidiana da colônia, pois

[...] havia oficinas para fabricação de utensílios domésticos, assim como tecelões, ferreiros, oleiros, sapateiros e demais artesãos que trabalhavam para suprir as necessidades diárias da vida cotidiana na colônia [...] (MÜLLER, 2009, p.6).

A transmissão de conhecimentos ligados à fabricação de utensílios domésticos, trabalho de tecelões, ferreiros, entre outros, tinha como característica principal a não sistematização, ou seja, estava baseada em conhecimentos elementares (reprodução hereditária), cuja aprendizagem muitas vezes se dava diretamente no local de trabalho, sem ambiente específico.

A priori, quando se observam as relações entre trabalho e educação nesse período, não se pode deixar de citar a importância da miscigenação entre os povos, notadamente entre negros e brancos. A partir desse contato, existiu uma troca de experiências e conhecimentos capaz de estabelecer algumas rupturas com o meio, sendo uma delas a necessidade de estabelecer uma relação de conhecimento com a produção final. Na relação entre sujeitos historicamente originários de contextos diferentes, "[...] o trabalho escravo perde prestígio progressivamente, em consequência das inovações e tecnologias, do encarecimento do cativo, da destruição das bases morais do regime [...]" (IANNI, 1988, p. 158). 
Assim, num processo de urbanização e miscigenação, as relações vão, aos poucos, ganhando novas necessidades e reestruturações, ainda a serviço de um Estado monopolizador. "O processo de transição do trabalho escravo ao trabalho livre foi, no entanto, lento e difícil" (COSTA, 1989, p.30).

O início do trabalho livre assalariado sofreu influência de causas econômicas nacionais e internacionais. A economia cafeeira, principalmente a partir da segunda metade do século XIX estava em ascensão no Brasil e faltava força de trabalho para a lavoura que demanda grande número de trabalhadores; desta forma, "[...] obrigava a pensar em alguma solução que importasse na substituição do trabalho escravo" (COSTA, 1989, p.111) devido aos rumores que pairavam sobre a proibição do tráfico negreiro e aos movimentos, cada vez mais organizados, pela libertação total da escravidão.

Historicamente, o início do trabalho livre surgiu principalmente a partir das levas imigratórias que se efetivaram de diversas maneiras, sendo o regime de parcerias ${ }^{3}$, o mais propagado e utilizado pela oligarquia capitalista. Esse contrato previa que, nas atividades laborais, haveria um acordo firmado entre os fazendeiros e os trabalhadores. Na prática, os fazendeiros propunham que um número variável de pés de café, previamente acordado, seria da família do trabalhador que os cultivasse, cuja venda seria dividida entre as partes, combinada antecipadamente no contrato, relacionando-se, assim, com a forma de produção servil oriunda do feudalismo europeu (MULLER, 2009).

Este regime de parceria, no decorrer do tempo, mostrou-se vulnerável, pois no final da produção e na partilha dos lucros, a divisão que deveria estar evidente para ambas as partes, devido à falta de leis, tornou-se obscura imbuindo-se numa relação de desconfiança, "[...] talvez fosse melhor pagar o 'alqueire de café a um preço fixo', combinado antecipadamente" (COSTA, 1989, p.125).

\footnotetext{
${ }^{3}$ Foi inicialmente incentivado pelo senador Nicolau de Campos Vergueiro, político e latifundiário paulista. Vergueiro traz para sua fazenda famílias de colonos suíços e alemães para trabalhar em regime de parceria, ao lado dos escravos (COSTA, 1989).
} 
Esse modelo de contrato propicia uma condição de produção desigual e contraditória. Em algumas regiões, "[...] a situação do trabalhador livre, não deveria ser muito melhor do que a do trabalhador escravo: sem propriedade, recebendo salários ínfimos [...]" (COSTA, 1989, p. 67). Porém, na sociedade capitalista "[...] à medida que a classe trabalhadora se integra à classe dominante, ela desenvolve modos de resistência e de autonomização que lhe permite construir seu próprio projeto contra-hegemônico (KUENZER, 1987, p.63)", ou seja, aos poucos, o trabalhador pode construir, por meio dessas relações antagônicas, um sistema próprio de resistência que, entretanto, por si só, não é capaz de modificar a estrutura e superestrutura estabelecidas.

No Brasil, por meio do incentivo do governo, houve a vinda de estrangeiros, principalmente, para os estados do Rio de Janeiro, São Paulo e Minas Gerais, fato decorrente da imigração ter sido considerada como uma forma de solucionar a falta de força de trabalho nas atividades oriundas das lavouras e, consequentemente, na indústria, pois se acreditava que viriam trabalhadores mais qualificados para substituir a força de trabalho servil então deixada em segundo plano.

Essa política adotada poderia, no entanto, ao longo do tempo apresentar-se para o Estado como um "perigo", devido à consciência política e resistência desses indivíduos, que poderiam reivindicar seus direitos. Portanto, os opositores à ideia de imigração, ou seja, os donos das terras apontavam que:

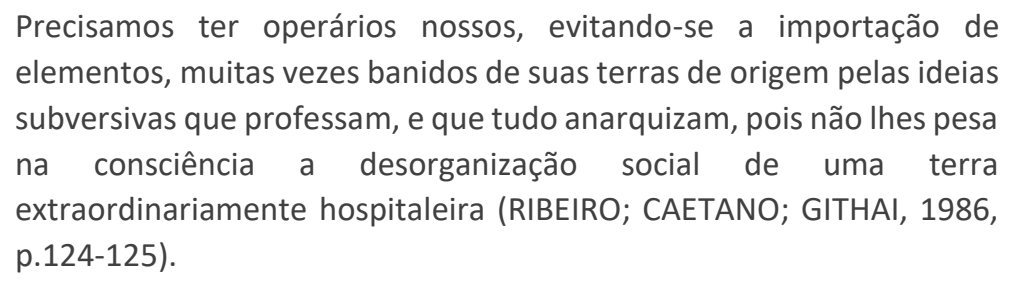
elementos, muitas vezes banidos de suas terras de origem pelas ideias subversivas que professam, e que tudo anarquizam, pois não lhes pesa na consciência a desorganização social de uma terra extraordinariamente hospitaleira (RIBEIRO; CAETANO; GITHAI, 1986, p.124-125).

Havia um esforço dos proprietários de terras, em fazer prevalecer a força de trabalho local, por existir receio de agregar trabalhadores estrangeiros que pudessem "desestruturar" os ambientes em que fossem inseridos. Percebe-se, assim, que os opositores acreditavam que a ordem social só poderia ser mantida por meio de relações sociais calcadas na submissão do trabalhador. 
De forma velada, propunha-se, também, que as escolas, nesse período, poderiam ser um valioso instrumento de consolidação da "ordem" social esperada. Com relação à apropriação do conhecimento escolar do Período Colonial, a

[...] função de socialização desempenhada pela escola, nesta época era reduzida, já que esta estava reservada a uma minoria de privilegiados. O processo de socialização, do conjunto da população, se dava através da educação assistemática, ou seja, o fundamental e indispensável para o desempenho dos papéis sociais inerentes a vida colonial, se aprendia no lar, na vida prática no convívio com os mais velhos, pela experiência de vida de cada um, etc. (FRANCO; SAUERBRONN, 1984, p. 28).

Observa-se, assim, o reducionismo da apropriação do conhecimento para a maior parte da população brasileira, respaldando-se num modelo classificatório, onde o exercício da socialização se daria no próprio contexto. Ademais, elenca-se que a educação no Período Colonial para negros e mestiços ocorria como um trabalho manual simplificado que, aos poucos, com as contribuições europeias a produtividade foi ganhando novas formas. Dentre as atividades voltadas à profissionalização dos negros e mestiços, estavam conhecimentos ligados à pecuária e artesanato, dentre outros (MULLER, 2009).

Também surgiram, no âmbito educacional, as Corporações de Ofícios, em que os mestres, através de práticas orientadas, ensinavam uma profissão aos aprendizes.

No Brasil, “[...] as corporações de ofício organizaram-se desde o início da colonização de acordo com os padrões da Metrópole portuguesa" (NASCIMENTO, 2009, p.60), ou seja, existia um controle na produção e execução dos ofícios. Esse modelo de aprendizagem profissional não era reconhecido sistematicamente e tampouco regulamentado por políticas públicas, porém, foram as Corporações de Ofício que formaram as bases para a posterior criação das Escolas Profissionais.

No período colonial existiam muitos indivíduos não alfabetizados devido à existência de escolas apenas para servir a uma pequena fração da sociedade - a classe dominante - gerando assim uma dissonância entre as pessoas que detinham recursos e as que nada ou pouco possuíam. Para a elite, existia o ensino secundário logo após as escolas de primeiras letras, mas para os trabalhadores em geral sobrava a possibilidade de buscar um ofício e tentar aprender 
uma profissão com o auxílio dos demais. Havendo dois modelos distintos de apropriação de conhecimento, pode-se afirmar que, a educação brasileira,

[...] ao longo da sua história, vem representando a própria dualidade da sociedade nacional, consubstanciada em uma acirrada e desigual distribuição do conhecimento. Assim, pode se afirmar que foi se tornando oficial e legitimado o grande distanciamento existente entre a educação da elite, caracterizada por uma maior qualidade e por seu caráter acadêmico, seletivo e propedêutico (ministrado em instituições secundárias e superiores) e a educação voltada para as camadas menos favorecidas, marcada pela qualidade questionável traduzida em um ensino pontual e aligeirado (ofertado em escolas primárias e profissionais) (AMARAL; OLIVEIRA, 2007, p. 167).

A apropriação do saber estava diretamente ligada ao poder econômico e social, diferenciado entre as classes, portanto, calcada na dualidade educacional.

Historicamente percebe-se que, a educação profissional não era percebida como uma atividade digna e reconhecida. Reflexo disso é que, entre 1840 e 1856, surgem as Casas de Educandos Artífices, onde os jovens que estavam em condição de mendigos nas ruas, eram encaminhados a tais casas, vistas pela sociedade como um ambiente assistencialista. Nesses locais, os jovens recebiam, na distribuição de conhecimento, dois modelos de ensino: um voltado à instrução primária, e o outro à aquisição de saber, nos ofícios ${ }^{4}$.

Mesmo considerando todas as vicissitudes inerentes à época e a própria situação econômica e política do país, a criação das casas de educandos artífices foram as primeiras tentativas de implementação do ensino profissional no Brasil (NASCIMENTO, V. M. 2007, p.67)

Assim, no campo ideológico e político, as iniciativas de ensinar se constituíam em formas de disciplinamento dos setores populares, com o objetivo de "[...] conter ações contra a ordem vigente e tornar legítima a estrutura social de exclusão herdada" (MANFREDI, 2002, p.28).

\footnotetext{
4 "A aprendizagem de ofícios abrangia o ensino de tipografia, encadernação, alfaiataria, carpintaria, marcenaria, tornearia, entalhe, funilaria, ferraria, serralheria, trabalhos em couro e sapataria" (NASCIMENTO, O., 2007, p.67).
} 
Em 1858, imbuídos de uma visão pré-capitalista de produção, houve a criação do Liceu de Artes e Ofícios no Estado do Rio de Janeiro, cujo objetivo era preparar os indivíduos para exercer um ofício, na perspectiva de uma vindoura industrialização, demonstrando, dessa forma, o caráter político incipiente de uma educação profissional capaz, na visão da elite, de preparar força de trabalho qualificada.

As mediações da educação para a formação de força de trabalho se deram como uma forma de evitar que os trabalhadores tivessem comportamentos contrários à ordem política, as quais entendiam que evitariam as mesmas indagações que já vinham aparecendo na Europa, além de favorecer um controle econômico dos trabalhadores.

A concepção de educação profissional era a de dar à "pobreza" um caráter considerado mais "digno", sendo também considerado um grande mecanismo de disciplinamento.

Nesse sentido, a função da escola foi a de ajudar a manter privilégios de classes, [...] quando se utilizou de mecanismos de seleção escolar e de um conteúdo cultural que não foi capaz de propiciar às diversas camadas sociais sequer uma preparação eficaz para o trabalho (ROMANELLI, 1998, p.24).

Esse modelo de seleção para o ingresso no ensino profissional se arrasta pela historicidade; portanto, as relações entre a educação e as necessidades econômicas são mais complexas do que se pode perceber.

Como decorrência de uma economia e de uma sociedade em constante movimento, é que o sistema educacional voltado à formação profissional vai tomando novos direcionamentos a partir do Período Republicano.

\section{Implicações nas relações entre trabalho e educação no Período}

\section{Republicano}

O Período Republicano, economicamente falando, foi de estímulos à produção agroexportadora além de ser também um período de significativos avanços em relação ao trabalho e à educação profissional, ou seja, no âmbito educacional, outras concepções foram sendo adicionadas às já existentes. 
A primeira criação oficial de uma educação voltada ao ensino profissional se deu através do Decreto no 7.566, de 23 de setembro de 1909, promulgado pelo então presidente Nilo Peçanha, através do qual foram criadas as Escolas de Aprendizes Artífices, as quais

[...] formavam, desde sua criação, todo um sistema escolar, pois estavam submetidas a uma legislação que as distinguia das demais instituições de ensino profissional mantidas por particulares (fossem congregações religiosas ou sociedades laicas), por governos estaduais, e diferenciavam-se até mesmo de instituições mantidas pelo próprio governo federal. Em suma, as escolas de aprendizes artífices tinham prédios próprios, currículos e metodologia próprios, alunos, condições de ingresso e destinação esperada dos egressos que as distinguiam das demais instituições de ensino elementar (CUNHA, 2000, p.94).

Tal decreto traz um discurso voltado à apropriação do conhecimento profissional, como um meio de acomodar a classe desafortunada ${ }^{5}$, a qual, necessariamente, não teria condições e, tampouco, instrumentos suficientes para uma ascensão social.

No governo de Nilo Peçanha, o Ministro Rodolpho Miranda, declarava que:

Considerando que um dos principais deveres do Governo da República é interessar-se pela sorte dos menores, principalmente dos desprovidos de meio de vencer e lutar pela existência, cabendo-lhe portanto ampará-los contra qualquer espécie de exploração que sobre ele possa exercer, o Ministério a meu cargo fez consistir em um dos seus primeiros atos a expedição do decreto n.7566 de Setembro de 1909, criando nas capitais dos estados, Escolas de Aprendizes Artífices, para o ensino profissional primário e gratuito. Procurou-se por essa forma, não só impedir a tendência da ociosidade, despertando-lhe o amor pelo trabalho, mas também converte-lo em criatura útil a sociedade, pelo aprendizado profissional, complementado pelo ensino teórico escolar (BRASIL, 1910).

Nesta declaração, é dever do Governo oportunizar aos indivíduos categorizados pelo ministro, como "desprovidos" e/ou ociosos, uma forma de estudar num ensino gratuito e voltado à profissionalização, e desta forma, mantê-lo como "homem ordeiro"6. 
Nilo Peçanha decretou que, em cada capital dos Estados da República, o Governo Federal deveria ofertar ensino profissional gratuito, para quantos alunos fosse possível comportar nos prédios (locados ou cedidos) destinados a este fim.

O objetivo, segundo ele, era transmitir conhecimentos nas oficinas e diminuir a marginalização e a ociosidade. Tal lei tinha como viés a implementação da educação profissional como atribuição do Estado enquanto reprodutor das relações de trabalho vigentes, ficando evidente que a educação voltada à profissionalização estaria a serviço dos trabalhadores, a fim de estabelecer sua acomodação às políticas públicas instauradas. Considera-se, desta forma, como um meio de reforçar ainda mais a divisão social de classes na sociedade capitalista.

Importante lembrar que o Ministério da Agricultura, Comércio e Indústria foi criado no governo presidencial de Nilo Peçanha, assim como o Serviço de Proteção aos Índios (SPI), inaugurando o ensino técnico no Brasil.

Já para a classe burguesa, a visão educacional era oposta, pois o ensino secundário seria,

[...] o reduto de formação humanista, e, portanto, aristocrático, impedia, no âmbito do sistema escolar, qualquer possibilidade de desenvolvimento e aceitação do ensino profissionalizante. Era uma barreira, antes de tudo, de natureza social e somente alterações de natureza social poderiam provocar mudança na posição da escola profissional no domínio do sistema escolar (NAGLE, 1974, p. 79).

Vale relembrar que parte da ideologia criada sobre o ensino profissional teve também a influência da Igreja Católica, a qual exerceu a sua contraposição ao ensino profissionalizante.

Nos discursos governamentais do Brasil, a educação profissional estava voltada à necessidade de força de trabalho, como ocupação dos marginalizados e oportunidade de aprender. Na prática, pré-estabelecia uma relação de poder do Estado, mediante as fragilidades na busca de sobrevivência e oportunidades da população pobre.

As políticas educacionais adotadas pelo Estado, no que diz respeito ao ensino profissionalizante, funcionavam como uma forma de "controle social", além de tentar estabelecer uma funcionalidade como "preceptor do povo", as quais, ideologicamente, seriam capazes de amenizar as situações de criminalidade, mendicância e marginalização das massas. O governo e os industriais viam as escolas como instituições piedosas e não integradas à 
estrutura de produção, além dos aspectos limitados impostos à "qualificação qualitativa (sic) mais ampla da mão-de-obra industrial" (FONTES, 1985, p. 24).

Assim, Nilo Peçanha criou 19 escolas de Aprendizes Artífices, cuja finalidade principal seria de "[...] qualificar os pobres e marginalizados para garantir os meios de produção de nível inferiorizado, subordinados ao Ministério da Agricultura, Indústria e Comércio" (KUENZER, 1997, p.18).

No modelo de organização das Escolas de Aprendizes Artífices, a característica principal era a divisão social das funções. Nas referidas escolas havia a produção de bens de consumo feitos pelo aluno e o docente (produtor de bens de consumo), sendo que os alunos eram considerados durante todo o processo apenas meros futuros operários assalariados.

Na sua criação, realizaram-se, no total geral, 2.118 matrículas com frequência de 1.248 alunos, evidenciando muitas evasões.

O propósito do Estado, ao criar as Escolas de Aprendizes Artífices, era promover ações que tivessem contribuição direta no desenvolvimento local e regional, com vistas ao aumento do capital e também com a intenção de organizar uma sociedade "ordeira". Portanto, embora

[...] relacionado às transformações sociais e econômicas que o Brasil vivia na época, o surgimento destas escolas [...] não pode ser apontado como decorrência direta das necessidades de mão - de - obra qualificada, em virtude do caráter incipiente do desenvolvimento industrial naquele período (CUNHA, 1977 apud KUENZER, 1997, p. 13).

Desta maneira, a criação das Escolas de Aprendizes Artífices não se deu, necessariamente, para promover um estímulo ao processo de industrialização ou tampouco para suprir as necessidades industriais, demonstrando assim, que se fosse realmente o caso, existiriam escolas apenas em locais industrializados. O que se percebe, então, é que o Governo Federal não teve a preocupação em verificar onde existiriam maiores possibilidades de demandas industriais, para então criar as escolas.

Nessa mesma fase de criação das Escolas de Aprendizes Artífices, “[...] regularizou-se o ensino agrícola o qual se estruturou em quatro categorias: Superior; Ensino Médio Agrícola; Aprendizados Agrícolas e Ensino Primário" (FRANCO; SAUERBRONN, 1984, p.42). 
A apropriação dos conhecimentos nas escolas de Aprendizes Artífices, ou seja, os ofícios ensinados nas dezenove escolas inauguradas eram marcenaria, sapataria e alfaiataria, entendidos muito mais como formação de um processo manufatureiro.

O modo de produção capitalista, no enfoque do processo de valorização por meio da manufatura,

[...] decompôs o ofício, formou os trabalhadores parciais e os combinou no trabalhado coletivo. Com a divisão manufatureira do trabalho realizou uma subdivisão qualitativa e uma proporcionalidade quantitativa dos processos sociais de produção, criando uma força social de trabalho, inserindo-se, assim, como forma eficaz de produzir mais-valia relativa (SILVA, 2005, p.94-95).

Os sujeitos envolvidos no processo participariam, na sociedade capitalista, como sujeitos determinantes da produção de mais-valia relativa7, pois, fariam com que o trabalho coletivo gerasse os bens necessários ao mundo do trabalho.

Com a implantação do decreto no 7.566, que deu origem às Escolas de Aprendizes Artífices, existiram algumas lacunas na sistematização do ensino, pois os espaços eram impróprios, faltavam equipamentos adequados, as oficinas tinham poucos equipamentos e a evasão escolar era frequente, pois a

[...] exclusão não se fazia paulatinamente, de um nível de ensino para outro, e sim, marcadamente, no início da escolarização, pois a grande maioria não tinha condições e em boa parte, nem interesse diante do regime de vida que estava submetida, em ingressar e permanecer na escola [...] (RIBEIRO, 1986, p. 32).

Além da exclusão propiciada pela escola, fosse pela escassez de recursos, a qual dificultaria o processo educacional de aprendizagem ou pela ausência de direcionamento

\footnotetext{
7 Segundo Marx (2003), a mais-valia absoluta é produzida pelo prolongamento do dia de trabalho e a mais-valia relativa é decorrente da contratação do tempo de trabalho necessário e da alteração quantitativa das partes componentes da jornada de trabalho. Isso quer dizer que é necessário que ocorra o aumento da produtividade, sem prolongar a jornada de trabalho, o que pressupõe a transformação das condições técnicas e sociais do processo de trabalho, a fim de encurtar o tempo socialmente necessário para a produção de uma mercadoria.)
} 
pedagógico, havia ainda a falta de condições econômicas dos alunos para se manterem na escola, sem desistirem.

Com a eclosão da Primeira Guerra Mundial (1914-1918), economicamente, o Brasil sofreu - dentre outras fragilidades - a crise na exportação do café e expressiva redução de investimentos na indústria, devido ao reflexo de desordem econômica internacional, trazida pela guerra.

Houve, também, alterações nas condições de comercialização do produto cafeeiro, evidenciando os limites de um país que não tinha um parque industrial compatível e, por este motivo, houve a necessidade de mudança de atitude do governo para a criação de uma política industrial concisa. No âmbito educacional, a Primeira Guerra Mundial foi também, o

\section{[...] período que encerrou qualquer possibilidade de manter o exercício de um outro idioma no sul do país, pois, embora se tratasse de um país democrático, a forte campanha pela nacionalização foi implantada de forma radical e isolando os indivíduos que não sabiam falar português (NASCIMENTO, 2004, p.139).}

Dessa forma, todo indivíduo nacionalizado ou estrangeiro que estivesse no Brasil, deveria obedecer à ordem vigente do Estado, caso contrário "[...] as empresas eram fechadas e o material recolhido; as escolas onde os professores não dominavam o idioma nacional eram fechadas" (NASCIMENTO, 2004, p.141).

Diante do período conturbado de guerra, em 11 de agosto de 1917, no governo de Venceslau Brás (1914 a 1918), criou-se no Rio de Janeiro a Escola Normal de Artes e Ofícios Venceslau Brás, cuja finalidade pioneira seria preparar e capacitar mestres e contramestres para ensinar nas escolas profissionais de todo o Brasil, pois, "[...] até este momento não existia qualquer outra escola voltada à superação do problema da falta de professores capacitados" (FRANCO; SAUERBRONN, 1984, p.49).

As relações entre trabalho e educação profissional daquele período continuavam marcadas pelo dualismo. Observa-se que havia discursos e práticas paralelas de uma concepção de melhoria da sociedade como um todo. Todavia, a classe operária, mesmo que participasse ativamente no processo de produção dos bens de consumo, por força do Estado, estaria condicionada a ideias muitas vezes vistas como repressoras e contrárias. 
Durante os primeiros anos de institucionalização da Escola de Aprendizes Artífices, para minimizar as evasões, houve distribuição da renda aos alunos pela produção executada durante o período letivo, além de uma espécie de ajuda de custo. Já no ano de 1918,

[...] o novo regulamento das Escolas de Aprendizes Artífices suprimiu o pagamento dos salários aos alunos. As propostas surgidas, nesse período, esbarravam, geralmente, no problema da falta de recursos, em razão da forte crise econômica que o país atravessava, agravada mais ainda com a primeira grande guerra. A partir de 1920, todavia, o ensino profissional toma vulto (FRANCO; SAUERBRONN, 1984, p.49).

Com a situação do ensino profissional precarizada e a população demonstrando insatisfação, a Câmara dos Deputados inicia algumas discussões para propor melhoria e ampliação das escolas profissionais.

Com o aval do Ministério da Agricultura, Indústria e Comércio, criou-se uma Comissão de técnicos especializados em educação profissional, chamada de Comissão Lüderitz ${ }^{8}$ cujo objetivo era observar e examinar o funcionamento dessas escolas. Essa comissão propôs, após algumas análises, que o ensino profissional deixaria de ofertar cursos apenas para aqueles que tinham menos condições financeiras, ampliando sua oferta. No capitalismo,

[...] a escola existe para distribuir desigualmente o saber, como resultado e condição da existência da divisão social e técnica do trabalho. Inverter essa função implica em inverter a própria relação entre capital e trabalho, através da superação do capitalismo (KUENZER, 1987, p.97).

Em 1922, foi apresentado na Câmara um projeto que previa um ensino industrial sem distinções, ou seja, os proletariados e os proprietários dos meios de produção teriam como ingressar no ensino profissional que, até então, estava direcionado apenas para os "desvalidos".

Contrariamente ao projeto, em 1924, iniciou-se no Liceu de Artes e Ofícios a Escola Profissional Mecânica no Estado de São Paulo, cujo eixo norteador era a qualificação de pessoas

8 Esta comissão estava composta por administradores e mestres do Instituto Parobé (RS) e deixou de existir por volta de 1930 (CUNHA, 2000). 
direcionadas ao trabalho nas ferrovias. Novamente, constata-se que o ensino profissional estava voltado a um determinado segmento profissional da sociedade e que as escolas eram criadas em função das demandas econômicas.

Ainda em 1924, devido à propagação de um ensino voltado a atender as indústrias, especialmente em São Paulo, surgiu a primeira iniciativa concreta de implantação do ensino profissional. Na época, um dos grandes protagonistas foi o Engenheiro Roberto Mange que,

[...] em 1923, fundou, junto ao Liceu de Artes e Ofícios de São Paulo, a Escola Profissional Mecânica, onde elaborou, com um grupo de estudiosos, as conhecidas séries metódicas de ofícios. [...] fundou o Instituto de Organização Racional do Trabalho (IDORT), destinado a: aumentar o bem estar social por meio de uma organização adequada a cada setor do trabalho e cada atividade; estudar, difundir e aplicar os princípios, métodos, regras e processos da organização científica do trabalho; evitar o desperdício sob suas múltiplas modalidades; dar o máximo de rendimento com o mínimo de toda segurança; quer sob o ponto de vista de atingir de forma plena a sua finalidade, quer sob o aspecto de eficiência qualitativa e quantitativa de operações. Assegurar administrações cientificamente exercidas. De 1940 a 1942, cuidou ele, em colaboração com outros expoentes da indústria, da fundação do SENAI, do qual foi o primeiro Diretor Regional em São Paulo, exercendo o cargo até sua morte em 1955 (BOLOGNA, 1980, p. 14).

Assim, num cenário de grande expansão ferroviária, surge a Escola Profissional Mecânica, cujo objetivo era suprir a força de trabalho ferroviária, num acordo estabelecido com as principais estradas de ferro do Estado (São Paulo e Sorocaba), sendo que cada cidade deveria destacar dois aprendizes para frequentarem um curso de quatro anos, com metodologia de ensino padronizado e estágios in loco.

Essa iniciativa, pioneira, alterava a realidade existente. Os estabelecimentos de ensino de ofícios, até então vinculados a um processo manufatureiro e, também, uma educação destinada aos desvalidos, passam a exercer um ensino prático e metódico, cujo objetivo primordial seria aproveitar as pessoas consideradas mais "aptas".

Nasceu, assim, o projeto de congregar em torno destes objetivos as ferrovias de São Paulo e o poder público. Foi com essa orientação que o "Instituto Racional do Trabalho" (IDORT)- de acordo com seus finsapós entendimento com as principais Estradas, apresentou ao Governo Estadual um plano geral de preparo e seleção do pessoal 
ferroviário, com a cooperação do Governo Estadual. Tornava-se, porém, mister instituir um órgão coordenador, o que ocorreu em 1934, por Ato do Governo de São Paulo, criando o “Centro Ferroviário de Ensino e Seleção Profissional" (CFESP), como entidade central, mantida pelas empresas ferroviárias do Estado (BOLOGNA,1980, p.15).

Os objetivos do IDORT eram mais amplos, buscando novos métodos de aprendizagem, de produção e de comportamentos, reforçando a "pedagogia do industrialismo nas escolas, nas fábricas, nas ruas, escritórios e até nos lares" (SENAI, 1991a, p.98 apud MÜLLER, 2009, p.99).

Devido à crise de 1929, a economia brasileira voltou-se para o mercado interno, deixando à demanda externa o papel de constituir o principal impulso dinâmico de crescimento (PEREIRA, 1984).

O Período da Primeira República foi marcado, no âmbito da educação profissional, por diversos movimentos e diferentes intervenções políticas, ora com discursos ideológicos reivindicatórios das classes trabalhadoras, ora sancionadas pelo poder do Estado, porém, concretamente o ensino profissionalizante só terá sua expansão consolidada durante o Estado Novo.

\section{Trabalho e Educação profissional no Estado Novo}

Durante o Estado Novo99, observaram-se importantes mudanças no ensino profissional, pois, nesse período ampliavam-se as primeiras indústrias e consequentemente os processos produtivos e "[...] tanto nas indústrias quanto nos transportes ferroviários, passaram a exigir trabalhadores dotados de qualidades" (CUNHA, 2000, p.06).

\footnotetext{
9 “O Estado Novo, foi instituído em 1937, é um ponto marcante [...] na medida em que se caracteriza pelo repúdio ao liberalismo político quanto por um repúdio ao liberalismo econômico. O Estado torna-se um importante produtor de bens e serviços de infraestrutura e abre caminho para o desenvolvimento industrial privado no país" (FRANCO; SAUERBRONN, 1984, p.49).
} 
Este foi, também, um período da Consolidação das Leis Trabalhistas (CLT) promulgadas pelo então presidente Getúlio Vargas como resposta às necessidades geradas pela industrialização.

No Brasil, muitas fábricas foram instaladas neste período através da aquisição, a preços baixos, de equipamentos de segunda mão provenientes de empresas estrangeiras que fecharam as portas (reflexo da Revolução Industrial).

O momento de transição de uma economia agroexportadora para uma economia industrial foi, também, causado por um crescente movimento de êxodo rural, que ampliou a oferta de força de trabalho para a indústria e, em alguns casos, devido ao surgimento de novos consumidores.

Os elevados valores dos produtos estrangeiros estimularam a produção interna, iniciando uma nova fase, a do processo de substituição das importações. O crescimento da produção industrial, que em 1933 ultrapassou a produção agrícola, registrou o crescimento do poder econômico a essa nova fração do empresariado.

Como demonstram os discursos de Roberto Simonsen, a industrialização era mais do que uma alternativa econômica, tratava-se de um projeto de transformação da sociedade, alicerçado na técnica e na ciência para o desenvolvimento do Brasil (MAZA, 2002).

O Centro Ferroviário de São Paulo (CFESP) “[...] criado em 1934, foi constituído pelas ferrovias do estado, com recursos provenientes do governo e das empresas, e contava com administração autônoma" (CUNHA, 2000, p.26). Tal centro ferroviário tinha como premissa a formação para o trabalho nas estradas de ferro; por isso, justificou-se que os alunos selecionados para essa modalidade de ensino eram filhos de ferroviários, e

[...] o ensino ferroviário orientado, coordenado e controlado pelo CFESP tinha por finalidade o fornecimento de conhecimentos técnicos específicos vinculados diretamente à organização do processo de trabalho nas ferrovias. Aí, o ofício já apresentava-se bem parcializado e o conjunto de operações exigidas para a realização do produto apresentava-se já codificado em operações bem definidas e distintas uma das outras, possibilitando a sua reconstrução "científica" pelos responsáveis administrativos das empresas (CAETANO, 1986, p. 271). 
Ressalta-se na implantação do ensino voltado à profissionalização que a introdução do modelo racional de aprendizagem, os procedimentos de pesquisas objetivas, a formação de profissionais especializados e a expansão do conhecimento mais tarde deu origem a metodologia de ensino adotada pelo SENAI. "[...] Em 1942 havia 16 escolas profissionais nas ferrovias paulistas, todas ligadas ao Centro". E neste mesmo ano "[...] haviam associado ao Centro nove ferrovias situadas fora do Estado de São Paulo" (BOLOGNA, 1980, p. 36).

Considerando a experiência educacional do CFESP, Euvaldo Lodi, no período presidente da Confederação Nacional da Indústria (CNI) e Roberto Simonsen, então presidente da Federação das Indústrias do Estado de São Paulo (FIESP), preconizaram um movimento em defesa da expansão do ensino profissional, como solução para atendimento às demandas da indústria brasileira. Esses empresários se comprometeram a assumir "[...] as responsabilidades pela organização e diferenciação de um organismo próprio, subordinado à Confederação Nacional da Indústria e às Federações de Industriais dos Estados [...]" (BOLOGNA, 1980, p. 20), com o objetivo de assegurar a implantação do ensino profissional, de acordo com o que estabeleciam e consequentemente, com o que interessava para melhor uma produção nas indústrias.

\section{A Lei Orgânica e a consequente criação do SENAI}

Considerando a institucionalização do ensino profissional, seja ela no ambiente das ferrovias, no interior das fábricas e até mesmo de maneira informal, o Estado começava a demonstrar que era necessário qualificar os trabalhadores. Assim, o

[...] atendimento à demanda da economia por mão-de-obra qualificada só vai surgir como preocupação objetiva na década de 40, quando a Lei Orgânica do Ensino Industrial cria as bases para a organização de um "sistema de ensino profissional para a indústria", articulando e organizando o funcionamento das escolas de aprendizes artífices (1942); é criado o SENAI- Serviço Nacional de Aprendizagem Industrial (1942) e o SENAC- Serviço Nacional de Aprendizagem Comercial (1946), resultantes do estímulo do Governo Federal à institucionalização de um sistema nacional de aprendizagem custeado pelas empresas para atender às suas próprias necessidades (KUENZER, 1997, p. 13). 
Quando da aprovação da Lei Orgânica do Ensino Industrial, inicia-se o processo de criação do SENAI, com base econômica oriunda da indústria, cujo objetivo final era garantir trabalhadores qualificados que pudessem atender as necessidades capitalistas industriais.

Desta forma, com a implantação da Lei Orgânica no 4.073, de 30 de Janeiro de 1942, as escolas passaram a ter uma proposta curricular prática e "[...] todas as escolas criadas em 1909 passam a oferecer cursos técnicos, além dos industriais e de aprendizagem"10 (KUENZER, 1997, p.13). A estruturação da Lei Orgânica é considerada,

[...] aspecto de indiscutível valor da história do ensino profissional, pois revela uma preocupação do Governo de engajar as indústrias na qualificação de seu pessoal, além de obrigá-las a colaborar com a sociedade na educação de seus membros. Esse fato decorreu da impossibilidade de o sistema de ensino oferecer a educação profissional de que carecia a indústria e da impossibilidade de o Estado alocar recursos para equipá-lo adequadamente (ROMANELLI, 1998, p.155).

O Brasil, sob o comando do Presidente Getúlio Vargas destacou-se, no âmbito educacional brasileiro,

[...] como mais oportuna e de imediata utilidade, entre outras medidas, a difusão intensa do ensino público, principalmente técnico - profissional, estabelecendo, para isso, um sistema de estímulo e colaboração direta com os Estados (CARONE, 1973, p.16).

Tal difusão de ensino profissional é acentuada, considerando que era um período de guerra e exigia um posicionamento na formação dos trabalhadores para a indústria, posto que as importações estavam dificultadas e necessitavam de aceleração na produção nacional. "Isto significava ter de expandir o setor industrial brasileiro e, com isso, absorver mais mão-de-obra (força de trabalho) qualificada. [...] Daí o recurso para o engajamento das indústrias no treinamento de pessoal" (ROMANELLI, 1998, p.155).

\footnotetext{
${ }^{10}$ A expressão "aprendizagem" aplicar-se-á a qualquer sistema em que o empregador se compromete, sob contrato, a empregar um jovem trabalhador e a ensinar-lhe ou mandar-lhe ensinar, metodicamente, um ofício, durante um período previamente fixado e em que o aprendiz é obrigado a trabalhar a serviço do referido empregador (LOPES, 1982, p. 16).
} 
Dessa forma, em 1942, a Lei Orgânica também conhecida como Reforma Capanema, proposta pelo Ministro Gustavo Capanema e sancionada pelo presidente Getúlio Vargas, concretizou a implantação do Serviço Nacional de Aprendizagem dos Industriários (SENAI), através do decreto-lei 4048 de 22 de janeiro de 1942.

O decreto-lei é o primeiro a consolidar as Leis Orgânicas do Ensino, além, de propiciar, com a intervenção do Estado, treinamentos e qualificações custeados pelo empresariado, ao mesmo tempo em que buscavam assegurar os treinamentos pertinentes à força de trabalho nas fábricas, entregando a administração direta do SENAI para a CNI- Confederação Nacional das Indústrias, o que provou, no decorrer da História, ser uma decisão em conformidade com o Estado, "[...] essa foi uma grande discussão na Constituinte que nós perdemos: a gestão tripartite deste recurso"(FRIGOTTO;CIAVATTA, 2002, p.16). Assim,

[...] o SENAI assumiu a organização jurídico-administrativa que o colocava fora do Estado por interferência dos seus dois idealizadores paulistas, Roberto Simonsen e Roberto Mange. Eles tiraram o SENAI da órbita de subordinação do Ministério da Educação ${ }^{11}$. Este perdeu o controle sobre o ensino industrial, depois da criação do SENAI. A entidade patronal dos industriais, CNI - Confederação Nacional da Indústria, irá se responsabilizar pelo processo de qualificação da força de trabalho, longe da direção e orientação pedagógica pretendida pela Superintendência do Ensino Profissional (RIBEIRO, 1986, p. 159).

O Estado não tinha nenhuma intenção de intervir ou mediar administrativamente o ensino profissionalizante preconizado pelo SENAI, pois este exercia o papel que o Estado desejava. Nesse sentido, o Estado caracteriza-se como,

[...] árbitro mediador, [o qual] procurará conciliar os diferentes interesses em jogo. O Estado não representando diretamente os interesses de nenhuma classe (ainda que fosse o representante das classes dominantes), encontrar-se-á em posição privilegiada para fortalecer-se, aparelhar-se repressivamente, intervir cada vez mais na economia e invadir a sociedade civil, subordinando-a cada vez mais ao

11 O Senai foi vinculado, desde sua criação, ao Ministério da Educação, o que só foi alterado pelo Decreto no 74.296, de 16 de julho de 1974, que o vinculou ao Ministério do Trabalho (CUNHA, 2000, p. 47). 
Sabe-se que o papel do Estado vem para reproduzir e reforçar mais a uma classe do que outra, afirmando, dessa forma, sua configuração aos interesses do capital. Entretanto, não poderia ser diferente, visto que o Estado vem, justamente, atender as necessidades da classe dominante. Porém, este não poderia dar visibilidade de representar os interesses somente dessa classe, portanto, cria-se através de políticas públicas, formas de representação da ordem social procurando impedir a luta de classes. Desta forma,

[...] a classe capitalista domina o Estado através de seu poder econômico global. Através de seu controle dos meios de produção, a classe dominante é capaz de influenciar as medidas estatais de uma maneira que nenhum outro grupo, na sociedade capitalista, pode desenvolver, quer financeira quer politicamente (CARNOY, 1988, p. 73).

No processo de consolidação do SENAl, o governo delegou à CNI, a elaboração de treinamentos, programas de ensino e a capacitação dos profissionais que iriam compor o quadro docente.

Foi somente com o Decreto-lei no 4.936, de 7 de novembro de $1942^{12}$, que o Serviço Nacional de Aprendizagem dos Industriários adquiriu a denominação, utilizada até o presente momento, de Serviço Nacional de Aprendizagem Industrial incluindo, assim, o ensino de ofícios (CUNHA, 2000).

Nesse contexto, os grupos de industriais estavam concentrados em indústrias de alimentação, de vestuário, de construção civil e mobiliária, de fiação e tecelagem, de artefatos de couro, joalheria e pedras preciosas, indústrias químicas e farmacêuticas, gráficas, indústrias de vidro e porcelana, indústrias metalúrgicas, mecânicas e de material elétrico além de transportes marítimos e fluviais (CUNHA, 2000).

\footnotetext{
12 Este mesmo decreto, “[...] dispôs sobre a obrigação de os estabelecimentos industriais empregarem aprendizes e menores num total de $8 \%$ correspondente ao número de operários neles existentes e matriculá-los nas escolas mantidas pelo Senai. Neste caso, a Lei ainda exigia prioridade para os filhos, inclusive os órfãos e irmãos, de seus empregados" (ROMANELLI, 1998, p.166).
} 
O SENAI foi fundado para atender o avanço industrial, com a expectativa de que em curto prazo preparasse o trabalhador que atuava e/ou atuaria na indústria; atingindo também os filhos de alguns desses trabalhadores. No entanto, havia uma preocupação nessa primeira fase, em relação à contratação de professores, os quais seriam os responsáveis em sistematizar o conhecimento, com o objetivo de assegurar aos industriais que haveria conhecimentos capazes de produzir com eficiência e em pouco tempo atendendo aos interesses capitalistas.

Assim, nos primeiros anos de atividade, a palavra de ordem era "velocidade". Roberto Mange tinha pela frente a tarefa de organizar, de forma rápida, uma estrutura que atendesse às necessidades do país em guerra, ao mesmo tempo em que precisava conquistar a confiança da sociedade em relação ao SENAI (SENAI, 1992, p.128, apud MULLER, 2009, p. 99).

Na fase inicial, "[...] a primeira providência para a implantação do SENAl foi à organização de um cadastro de empresas industriais em todo o país, sua localização e o número de empregados de cada uma delas" (CUNHA, 2000, p.56). Posteriormente, deu-se a angariação dos imóveis cedidos ou locados e, por fim a execução dos cursos.

Nesse encaminhamento de valorização e fortalecimento do capital industrial, utilizandose do capital humano é que a criação do SENAI se apresentava num viés de que "[...] o processo produtivo, através de treinamentos especiais ou de aprendizado durante o próprio trabalho, o que é mais comum, emulado por suas pretensões de ascensão profissional" (KUENZER, 1997, p. 53), constituía-se uma das teorias utilizadas pelo SENAI.

Para organizar a contratação de professores, em curto prazo, também foi oferecido aos profissionais que trabalhavam no Estado, salários superiores aos recebidos, a fim de suprir as disciplinas contidas como regulares, ou seja, português e matemática. Já nos assuntos específicos, os profissionais passavam por testes seletivos. Demonstrou-se, no entanto, que esta última possibilidade de angariação de profissionais não teve o êxito desejado, exatamente por ocorrerem várias contratações sem o perfil considerado mais apropriado (MULLER, 2009).

No que se refere aos alunos da modalidade de ensino profissional, percebe-se que, na composição dessas turmas, a prioridade seria atender às demandas industriais da época,

[...] ao contrário das modalidades de recrutamento das escolas de aprendizes artífices, de forte conteúdo ideológico ligado ao assistencialismo, as novas escolas industriais previam a realização de 


\begin{abstract}
"exames vestibulares" e de testes de aptidão física e mental. A pobreza deixava de ser, então, critério suficiente para o aprendizado de um ofício, embora não perdesse seu caráter necessário. A aptidão para um ofício, incluindo aí as atitudes consideradas adequadas para o desempenho de uma atividade industrial qualquer, passava a ser um fator prioritário na admissão (CUNHA, 2000, p. 36).
\end{abstract}

Sabe-se que, anteriormente às Leis Orgânicas, verificou-se uma educação profissional voltada ao assistencialismo e, posteriormente às Leis, esperava-se que, na composição das turmas houvesse alunos com rendimento escolar mais significativo, tendo em vista o crescimento histórico da rede de escolas primárias mantidas pelo Estado e pelos municípios.

A primeira implantação de uma escola do SENAI ocorreu na cidade de São Paulo, denominada de Escola SENAI "Roberto Simonsen". Começou a funcionar em 28 de agosto de 1942 sob a direção de Roberto Mange

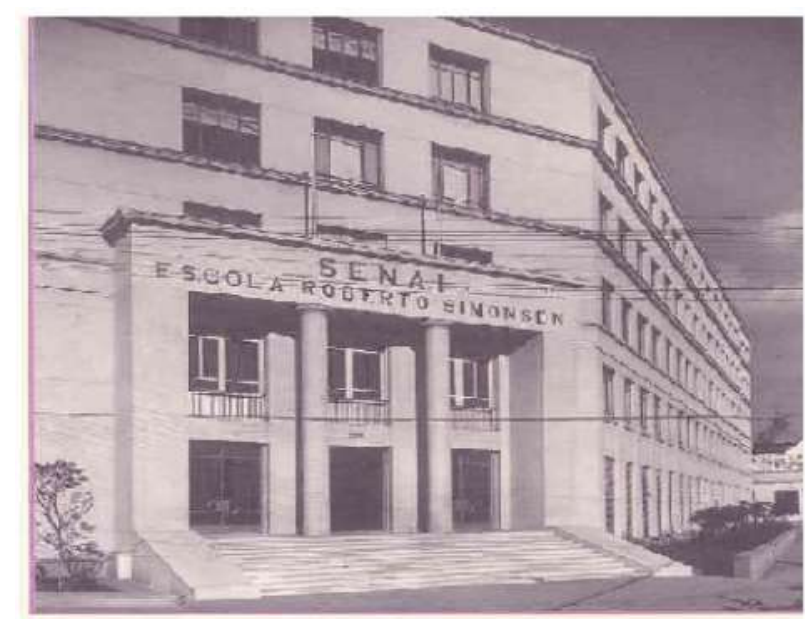

Figura 1 - Primeira Escola do SENAI

Fonte: SENAI 1991.

Na imagem acima, verifica-se que

[...] as primeiras escolas do SENAI construídas em São Paulo tinham um aspecto imponente, estilo aproximado ao neoclássico, e partiam que o mais importante eram as oficinas. Por isso, estas ficavam localizadas junto à rua, separadas apenas por grandes painéis de vidro [...] (CUNHA, 2000, p.59).

Mange, na direção da Escola SENAI Roberto Simonsen, era percebido pelo presidente Getúlio Vargas como representante de programas que poderiam ser aplicados no ensino profissional, por possuir vasta experiência na aplicação do método racional do trabalho e por 
ser detentor de um saber intelectual considerado suficientemente capaz de trazer eficácia ao SENAI.

O desenvolvimento industrial da cidade de São Paulo, naquele ano de 1942, era impulsionado pelo sistema ferroviário, que se constituía como um portal de escoamento da produção agrícola originária do interior.

Nos espaços onde se iniciaram os cursos do SENAI, percebe-se que, ao contrário do que estava prescrito nos documentos relativos à sua criação, ocorreram cursos de acordo com a demanda industrial.

Nas escolas SENAI era aplicada a metodologia racional do trabalho e acrescenta-se que, oposto às Escolas de Aprendizes Artífices, o SENAI não foi criado de forma aleatória na maioria dos Estados brasileiros; a preocupação para sua institucionalização era o número de indústrias instaladas em cada Estado (CUNHA, 2000).

No decorrer do ano de 1942, foram instaladas em São Paulo, 19 escolas do SENAl e, no Brasil, nessa primeira implantação, ficaram de fora apenas os Estados do Espírito Santo, Amazonas e Goiás. Com relação aos recursos financeiros, com a criação de cada escola, o SENAI

[...] demonstrou, desde o início, vocação para a administração das escolas nos moldes empresarias. Em 1942, através da FIESP [Federação das Indústrias de São Paulo], um corpo técnico do SENAI visitou o incrível número de 8.122 indústrias na capital paulista. A partir dos dados ali colhidos, o Departamento de Controle passou a supervisionar as empresas para garantir que todas fizessem 0 recolhimento devido ao SENAI (MULLER, 2009, p. 159).

A implantação das escolas do SENAI deu-se de forma rápida, em decorrência da oferta do ensino e o órgão logo ficou reconhecido pelo Estado e pela população. O SENAI constitui-se como uma instituição privada, sendo que suas políticas são instauradas pela CNI, que possui como uma das suas responsabilidades o repasse de recursos financeiros oriundos das indústrias. $\mathrm{O}$ diretor da $\mathrm{CNI}$ é designado pelos sindicatos patronais.

No primeiro ano de sua consolidação, atendeu principalmente aos operários, que no interior das fábricas, já estavam trabalhando, procurando adaptá-los às novas máquinas, pois

[...] estava claro, desde o princípio, que a formação de profissionais não gera, por si, oportunidades de trabalho. Muito pelo contrário, são 
as necessidades indicadas pelo setor produtivo que devem orientar os rumos da formação profissional (SENAl, 2007, p.70).

Não existia uma preocupação em instruir profissionalmente um número inferior à demanda industrial. Ao contrário, o que se observa é que a instituição formava operários em número maior do que a demanda, criando um "exército de reserva". Marx e Engels (1994) destacam que o objetivo de garantir um exército reserva é aumentar a exploração da força de trabalho e a consequente acumulação capitalista na redução de salários.

A maioria dos cursos, nesse primeiro momento, estava ligada à área metal-mecânica (ajustagem, caldeiraria, ferraria, solda elétrica, tornearia mecânica, fiação). Mais tarde, muitos destes cursos deixaram de existir devido à própria demanda industrial (CUNHA, 2000).

Devido às inúmeras dificuldades de importação, a improvisação e a manutenção dos equipamentos exigiram operários qualificados. Portanto, para se consolidar, o SENAI precisou de máquinas, as quais foram produzidas pelos docentes e discentes, para atender às necessidades do ensino dos ofícios ligados à mecânica; prédios foram construídos e a maior parte deles ocupados mediante cessão; instrutores recrutados nas indústrias; séries metódicas elaboradas para as mais diversas especialidades (CUNHA, 2000).

O SENAI era percebido como um ambiente educacional que promovia controle e preocupava-se não só com a apropriação de conhecimentos mas também com o civismo e valores morais, cuja ideologia seria capaz de manter a ordem nas relações de produção industrial. Todavia, a própria

\footnotetext{
[...] concepção do SENAI refletia o conceito de Mange de uma hierarquia industrial composta rigidamente, em ordem ascendente, por trabalhadores não - especializados (braço anatômico), trabalhadores semiespecializados (braço atento), operários especializados (braço pensante), e encarregados da supervisão (braço pensante e dirigente). Nas palavras de Euvaldo Lodi, pronunciadas na inauguração da Escola Roberto Simonsen do SENAl: 'Nas escolas industriais do SENAI, a ordem primorosa, a pontualidade exata, a limpeza irrepreensível, a obediência constante, os sentidos de hierarquia constituem lições vivas que embebem todos os jovens (WEINSTEIN, 2000, p.145 apud LIMA, 2017, p.33)
}

No ambiente das oficinas utilizava-se o método de instrução individual, composto por quatro fases: estudo da tarefa, no qual o aluno lia as folhas e buscava as possíveis soluções, 
elaborando seu roteiro de trabalho; na sequência o professor demonstrava a execução das tarefas de forma repetitiva; posteriormente a execução da tarefa, ou seja, o discente realizava na prática a atividade da folha e o docente auxiliava e por último, e não menos importante, a avaliação, preponderando além da execução da tarefa, o manejo com as ferramentas e as questões comportamentais (CUNHA, 2000).

Um dos métodos mais utilizados pelos professores era a repetição de atividades, pois, considerava que quanto maior fosse a repetição, melhor seria a assimilação.

Analisando o processo numa perspectiva pedagógica, “[...] O SENAI tem o cuidado de não ensinar além do que a empresa exige, para não frustrar o aprendiz no seu futuro emprego [...]" (FRIGOTTO, 1977, p.68). A educação profissional era voltada para atender apenas a uma fração do contexto social, ou seja, os industriais. Já o instrutor teria a função de ensinar as técnicas para a conduta dos trabalhadores na fábrica além de, imbuir valores capazes de promover a vida em sociedade. $\mathrm{O}$ aluno ${ }^{13}$, por sua vez, apresentava ideias condicionadas no meio destes interesses e um deles relata que,

[...] os instrutores tratavam a gente com muito carinho. Eu não sei como é hoje, mas, naquela época, a gente tinha no instrutor o espelho de pessoa que a gente queria ser. Por que eles eram não apenas pessoas mais preparadas profissionalmente, mas pessoas que se preocupavam quando a gente não fazia uma coisa legal. Ao invés de dar bronca, vinham conversar, vinham orientar a gente. Então a gente tinha o instrutor como uma espécie de paizão (SENAI, 1992, p. 120).

Esse depoimento reforça o papel da escola do SENAI, na figura do instrutor, reconhecido como modelo ideal a instruir os alunos que, desta forma, poderiam compreender "sem desordem", as atitudes que seu patrão pudesse vir a ter no ambiente de trabalho, sendo, portanto, articuladores com os interesses ideológicos capitalistas.

Para Mange, o aluno que saísse do SENAl, depois de ter participado de cursos com as características acima mencionadas, seria

${ }^{13} \mathrm{O}$ depoimento é do ex-presidente Luís Inácio Lula da Silva, ex-aluno do Senai 
[...] um cidadão, uma personalidade bem ajustada, que pudesse ser colocada a serviço da comunidade. Não adiantaria ter um profissional bem treinado, cujos objetivos fossem antissociais ou associais (BARROS SANTOS, 1990 apud SENAI, 1991a, p.154).

Os centros de formação profissional do SENAI encerravam a aprendizagem com um curso destinado a um estágio de iniciação na indústria, quando então estudariam o organograma das empresas, prevenção de acidentes, legislação trabalhista, entre outros. Esses cursos duravam em média 10 meses e eram acompanhados, de forma esporádica, pelo monitor do SENAI, o qual deveria avaliar se os alunos respeitavam as regras de pontualidade e as demais normas da empresa; se eles tinham iniciativa e, por fim, se o aprendiz atendia a determinados critérios para, só assim, receber seu certificado.

Na busca pela padronização do método, do docente e do material didático, é que o ensino profissionalizante do SENAI dava seus primeiros ensaios em busca de consolidação (CUNHA, 2000).

O modelo de suas instalações físicas deveria estar o mais parecido com as empresas, ou seja, na entrada o aluno deveria entregar sua caderneta de presença, parecida com um cartão ponto, onde seriam anotadas as faltas, atrasos, entre outros. O aprendiz do SENAI não poderia ter intervalo de lanche, que era levado na sala para não interromper sua aprendizagem. Ressalta-se ainda que não poderiam existir conversas, não entravam visitantes nas instalações e, no final do dia, deveriam se retirar do ambiente de forma harmônica e sem barulho (CUNHA, 2000).

Somente através da disciplina e ordem os alunos poderiam ser capazes de corresponder às necessidades da força de trabalho industrial vigente.

Não obstante esses traços possam se constituir em elementos, talvez os mais importantes para a funcionalidade dos egressos do SENAI nas organizações industriais, cabe perguntar sobre até que ponto esse tipo de aprendizado conduziria a uma acomodação ao status de operário e de conformismo a certa ordem social? (FRIGOTTO, 1977, p.168).

Na condução de um ensino profissional moldado para atender as regras da sociedade capitalista, aparentemente se exclui a subjetividade do indivíduo, visto que nas suas relações com a sociedade, isso parece não ter importância, demonstrando que, 
[...] se compararmos o processo de produzir valor com o processo de trabalho, verificaremos que este consiste no trabalho útil que produz valores-de-uso ${ }^{14}$. A atividade neste processo é considerada qualitativamente, em sua espécie particular, segundo seu objetivo e conteúdo. Mas, quando se cogita da produção do valor, o mesmo processo de trabalho é considerado apenas sob o aspecto quantitativo. Só importa o tempo que o trabalhador leva para executar a operação ou o período durante o qual a força de trabalho é gasta utilmente (MARX, 1994, p.220).

Na sociedade industrial a produção do capital, bem como sua valorização, remete diretamente à estabilidade do modo de produção capitalista, e na formação do trabalhador.

Em 1943, pesquisas apontam que havia 34 escolas SENAI abertas [...] sendo as três primeiras no Estado do Rio de Janeiro, São Paulo e Minas Gerais, [...] além de sete cursos em escolas já existentes, sendo que 6.000 alunos, entre adultos e aprendizes haviam sido atendidos (MULLER, 2009, p.158).

Tal expansão e adesão deve-se ao fato de que, nos seus discursos sociais, o SENAI apresentava-se como uma instituição educacional capaz de resgatar e oportunizar aos trabalhadores meios de inserir-se na sociedade capitalista industrial, trazendo consigo o convencimento. De modo geral, a educação voltada à profissionalização é resultado, também, da historicidade dos homens enquanto sujeitos que necessitam de sobrevivência material.

Compreende-se, assim, a importância deste artigo e sobretudo, enquanto sujeitos históricos, na compreensão das relações de trabalho na sociedade e consequentemente as questões educacionais profissionais que permearam o desenvolvimento capitalista, estabelecendo um processo reflexivo sobre a luta de classes e os interesses contra hegemônicos presentes na sociedade.

\footnotetext{
${ }^{14}$ Valor de uso no pensamento marxista refere-se ao trabalho que atende à necessidade humana
} 


\section{Referências}

AMARAL, C. T. de; OLIVEIRA. M. A. M., Educação profissional: um percurso histórico, até a criação e desenvolvimento dos cursos superiores de tecnologia. In: FIDALGO. F.; FIDALGO. N. L.; OLIVEIRA. M. A.M. (Orgs.), 2007 Petrópolis, RJ: Vozes, 2007, p. 167-206.

BOLOGNA, I. Roberto Mange e sua obra. [S.I.]: Unigraf, 1980.

BRASIL, Ministério da Agricultura, Indústria e Comércio. Relatório do Ministro da Agricultura, Indústria e Comércio para 1910. Disponível em <https://repositorio.ufsc.br/bitstream/handle/123456789/181796/Relat\%C3\%B3rio\%20da\%20 Escola\%20de\%20Aprendizes\%20Art\%C3\%ADfices\%20\%2819091910\%29.pdf? sequence=1\&isAllowed=y $>$ acesso em 20/03/18.

CAETANO, C. G. Qualificação e ferrovias: A Experiência das Escolas ferroviárias (1920-1945). In: RIBEIRO, M. A. R. (Org.). Trabalhadores Urbanos e Ensino Profissional. 2. ed. Campinas: Editora da UNICAMP, 1986. p. 270 - 281.

CARNOY, M. Estado e teoria política. 2. ed. Campinas, São Paulo: Papirus, 1988.

CARONE, E. A segunda República: 1930-1937. Rio de Janeiro: Difusão Europeia do Livro, 1973.

COSTA, E. V. da. Da senzala à colônia. 3. ed. São Paulo: Brasiliense, 1989.

CUNHA, L. A. $O$ ensino de ofícios artesanais e manufatureiros no Brasil escravocrata. 2. ed. São Paulo: Editora UNESP; Brasília, DF: FLACSO, 2000.

CUNHA, L. A. O Ensino Profissional na Irradiação do Industrialismo. São Paulo: ed. UNESP, 2005. FONSECA, C. S. História do Ensino Industrial no Brasil. Vol.3, 2. ed, Rio de Janeiro. SENAI/DPEA, 1986.

FONTES, L. B. Formação profissional \& produtividade do desempenho humano. Rio de Janeiro: SENAI/DN, 1985.

FRANCO, L. A; SAUERBRONN, S. Breve histórico da Formação Profissional no Brasil. São Paulo: CENAFOR, 1984.

FRIGOTTO, G. Efeitos cognitivos da escolaridade do SENAI e da Escola Acadêmica: uma pedagogia para cada classe social? 1977. 158 f. Dissertação (Mestrado em Educação) FGV/IESAE, Rio de Janeiro, 1977.

FRIGOTTO, G; CIAVATTA, M. (Orgs.). A experiência do trabalho e a educação básica. Rio de Janeiro: DP\&A, 2002.

IANNI, O. A metamorfose do escravo: apogeu e crise da escravatura no Brasil. São Paulo: Hucitec; Curitiba: Scientia ET labor, 1988.

KUENZER, A. Z. Educação e trabalho no Brasil: o estado da questão. Brasília: INEP/MEC, 1987.

. Ensino de 2o grau: o trabalho como princípio educativo. São Paulo: Cortez, 1997.

LIMA, D.D. A Formação Do Pequeno Operário Na Escola Senai-Pr - A Reprodução Ideológica Presente No Jornal "O Escudo". 2017, 276f. Tese (Doutorado) - Universidade Estadual de Campinas, São Paulo, 2017. 
LOPES, S. Uma saga da criatividade brasileira. Rio de Janeiro: SENAI - DN, 1982.

MANFREDI, S. M. Educação Profissional no Brasil. São Paulo: Cortez, 2002.

MARX, K. O Capital: Crítica da economia política. Livro 1. Trad.: Reginaldo Sant'Anna. Rio de Janeiro: Bertrand Brasil, 1994. Vol. I e II.

MAZA, F. O idealismo prático de Roberto Simonsen: ciência, tecnologia e indústria na construção da nação. 2002, 276f. Tese (Doutorado)- Universidade de São Paulo. São Paulo, 2002.

MULLER, M. T. A lousa e o torno: a escola SENAI Roberto Mange de Campinas. 2009, 334f. Tese (Doutorado) - Universidade Estadual de Campinas, São Paulo, 2009.

NAGLE, J. Educação e sociedade na Primeira República. São Paulo: E.P.U/E.D.U.S.P, 1974.

NASCIMENTO, M. I. M. A Primeira Escola de professores dos Campos Gerais-PR, 2004, $225 f$. Tese (Doutorado em Educação) - Universidade Estadual de Campinas, 2004.

NASCIMENTO, M.N.M. História, trabalho e educação: relações de produção da força de trabalho na agroindústria canavieira. 2009, 255f. Tese (Doutorado em Educação) - Universidade Estadual de Campinas, 2009.

NASCIMENTO, O.V. Cem anos de Ensino Profissional no Brasil. Editora Curitiba IBPEX, 2007.

NASCIMENTO, V. M. do. Ensino Técnico no Paraná: análise de sua trajetória. 2007,153f. Dissertação (Mestrado em Educação) - Pontifícia Universidade Católica do Paraná, Curitiba, 2007.

PEREIRA, J. C. Formação industrial do Brasil e outros estudos. São Paulo: Hucitec, 1984.

RIBEIRO, M. A. Qualificação de Forca de Trabalho: A Experiência das Escolas Profissionais do Estado de São Paulo 1911/1942 In: RIBEIRO, M. A. R. (Org.). Trabalhadores Urbanos e Ensino Profissional. 2. ed. Campinas: Editora da UNICAMP,1986.

RIBEIRO, M. A.; CAETANO, C. G.; GITAHI, M. L. C. Trabalhadores urbanos e ensino profissional. 2. ed. Campinas: Editora da Unicamp, 1986.

ROMANELLI, O. de O. História da Educação no Brasil (1930/1973). 20. ed. Petrópolis, Vozes, 1998.

SENAI, SENAI, SP: 65 anos de um sistema educacional consequente. São Paulo: SENAI, 2007.

Projeto Memória: De homens e máquinas: Roberto Mange e a formação profissional. Volume 1. São Paulo: SENAI, 1991a.

Projeto Memória: De homens e máquinas: Acervo Roberto Mange. Inventário Analítico. São Paulo: SENAI, 1991b.

Projeto Memória: O Giz e a Graxa: meio século de educação para o trabalho. Projeto Memória do SENAI-SP, São Paulo: SENAI, 1992.

SILVA, S. T. A qualificação para o trabalho em Marx. 2005, 272f. Tese (Doutorado em Educação) - Universidade Federal do Paraná, Curitiba, 2005.

Recebido em: 13/09/2017

Aceito em: 19/02/2018 